\title{
AFETUOSOS ABRAÇOS E SAUDADES CARTAS DE MURILO MENDES A ANTONIO CANDIDO
}

\author{
MENDES, Moema Rodrigues Brandão ${ }^{1}$
}

\begin{abstract}
RESUMO: O fio condutor desta reflexão é divulgar, enquanto fonte de pesquisa literária, a correspondência enviada pelo poeta Murilo Mendes ao crítico, Antonio Candido e sua esposa, Gilda de Mello e Souza. Tal correspondência se encontra sob a guarda do Museu de Arte Murilo Mendes (MAMM) administrado pela Universidade Federal de Juiz de Fora (UFJF) nesta mesma cidade em Minas Gerais. São 18 mensagens datadas de 1958 a 1972, distribuídas em 16 cartas e 2 cartões enviados de Roma e de Lisboa. A doação deste lote epistolográfico foi uma ação do ensaísta Antonio Candido no ano de 2009 aconselhado pelo estudioso Murilo Marcondes de Moura que intermediou a captação e entrega deste material ao referido Museu. A relevância desta pesquisa se justifica pelo fato de que nos arquivos, públicos e privados, estão depositadas informações importantes que contribuem para compreensão dos processos sociocultural, intelectual e literário de uma época. É significativo ressaltar que estes documentos de correspondência que estão sendo depositados, em instituições públicas como museus e fundações de importância literária, sejam recolhidos, guardados e preservados no fundo arquivístico do titular em questão com o objetivo de sediar novas pesquisas nesta área do conhecimento.
\end{abstract}

PALAVRAS-CHAVE: Murilo Mendes, Antonio Candido, Correspondência, Arquivos.

\section{AFFECTIVE HUGS AND NOSTALGIA LETTERS FROM MURILO MENDES TO ANTONIO CANDIDO}

\begin{abstract}
The thread of this reflection is to disclose, as a source of literary research, the correspondence sent by the poet Murilo Mendes to the critic, Antonio Candido and his wife, Gilda de Mello e Souza. Such correspondence is under the custody of the Murilo Mendes Art Museum (MAMM) administered by the Federal University of Juiz de Fora (UFJF) in this same city in Minas Gerais. There

\footnotetext{
${ }^{1}$ Doutora em Letras (UFF/RJ), Pós-doutoranda na linha de pesquisa Resgate (Fundação Casa de Rui Barbosa/RJ). Professora titular do Programa de Pós-graduação Stricto sensu/ Mestrado Acadêmico em Letras do Centro de Ensino Superior de Juiz de Fora (CES/JF), membro do Conselho Curador do Museu de Arte Murilo Mendes (MAMM/JF). Membro da diretoria da Associação de Pesquisadores em Crítica Genética (APCG/USP). moemarbmendes@gmail.com
} 
are 18 messages from 1958 to 1972, distributed in 16 letters and 2 cards all sent from Rome and Lisboa. The donation of this epistolografic lot was an action of the essayist Antonio Candido in 2009, advised by the scholar Murilo Marcondes de Moura, who mediated the collection and delivery of this material to the said Museum. The relevance of this research is justified by the fact that the archives, public and private, contain important information that contributes to the understanding of the sociocultural, intellectual and literary processes of an era. It is noteworthy that these correspondence documents that are being deposited in public institutions such as museums and foundations of literary importance are collected, stored and preserved in the archival fund of the holder in order to host new research in this area of knowledge.

KEYWORDS: Murilo Mendes, Antonio Candido, Correspondence, Archives.

\section{INTRODUÇAO}

Se pusesse novamente as mãos nestas cartas, será que eu gostaria de lê-las, de mergulhar no seu passado? Elas mereceriam se tornar públicas? Antoine Compagnon

Recortes de jornais, cartas e cartões postais são algumas peças que os indivíduos guardam e que vêm a constituir a formação de uma subjetividade social. A junção deste material pelo titular compõe uma das principais concepções da memória e suas manifestações na cultura, entendendo memória como registro vivido, preservado com resgate de imagens e reconstrução da experiência humana (COSTA, 2010).

O estudo da construção e manutenção da memória, no contexto dos estudos literários, pode ser feito sob o enfoque da correspondência como patrimônio da cultura, ou seja, a correspondência como elemento de compreensão da manutenção de lembranças na história da formação do homem, enquanto ser histórico, social e ao mesmo tempo, indivíduo particular.

Com a finalidade de preservar esses itens, alguns escritores têm depositado tal documentação em instituições tais como fundações, institutos, bibliotecas e museus, cujo objetivo é a preservação da memória cultural de uma época.

Os acervos de documentos custodiados nestes centros de informação são denominados de arquivos pessoais e, especificamente no caso de dossiês pertencentes a escritores, a nomenclatura agrega mais um adjetivo: arquivos pessoais literários. 
Os arquivos pessoais são instrumentos culturais que servem de referência para a construção e permanência da memória coletiva e são esclarecedores quanto ao desenvolvimento da pesquisa histórica. Conforme Louis Hay (2003, p. 68), “documentos literários passaram a ser colecionados a partir do momento em que o culto ao grande escritor surgiu no imaginário coletivo".

A partir destas reflexões, evidencia-se que a maior parte dos documentos guardados nos arquivos são cartas, sobre o que a pesquisadora Eliane Vasconcellos, da Fundação Casa de Rui Barbosa (AMLB/FCRB), (2008, p. 382) nos instrui, afirmando que "durante muito tempo, a correspondência permaneceu sepultada nos arquivos públicos ou privados e recentemente passou a ter valor como fonte primária”. Sobre esta consideração, Maria Zilda Ferreira Cury (1983) adverte que a pesquisa nos muitos acervos e arquivos que ainda permanecem praticamente intocados em nosso país deve ser incorporada aos estudos acadêmicos como material importante para a literatura e para a historiografia literária.

O fio condutor desta reflexão é, portanto, divulgar, enquanto fonte de pesquisa literária, a correspondência enviada pelo poeta Murilo Mendes ao crítico Antonio Candido de Mello e Souza e sua esposa, Gilda de Mello e Souza.

Esta correspondência encontra-se sob a guarda do Museu de Arte Murilo Mendes (MAMM) administrado pela Universidade Federal de Juiz de Fora (UFJF) nesta mesma cidade em Minas Gerais, alocado no Fundo do titular. São 18 mensagens datadas de 1958 a 1972, distribuídas em 16 cartas e 2 cartões enviados de Roma e de Lisboa.

Para uma melhor apreciação do conteúdo das cartas, levando em consideração que não foram localizadas as cartas assinadas pela família Mello e Souza, é importante contextualizar os correspondentes, que neste lote epistolográfico conhecemos somente pela voz de Murilo Mendes. Para isso, foram consultadas fontes biográficas de cada um deles.

Segundo Júlio Castanõn Guimarães,

Murilo Monteiro Mendes, mineiro de Juiz de Fora, nasceu em 13 de maio de 1901. Casou-se em 1947, aos 46 anos de idade com a poetisa Maria da Saudade Cortesão, filha do grande historiador e poeta português Jaime Cortesão que estava exilado no Brasil por se opor ao governo ditatorial de Salazar, estabeleceu-se, então, com a família, Cortesão, no Rio de Janeiro (GUIMARÃES, 1986, p. 14). 
Guimarães (1986) informa ainda que a primeira viagem de Murilo Mendes à Europa aconteceu em 1952, a segunda, em 1953, e em 1955, o poeta transitava entre a Bélgica e a Holanda, proferindo conferências em universidades, não somente sobre literatura brasileira, mas sobre cultura, artes plásticas, arquitetura e música. Murilo Mendes faleceu em 1975, em Lisboa, Portugal, no dia 13 de agosto.

Antonio Candido de Mello e Souza, segundo Alvarenga (2015),

[..] nasceu em 1918, no Rio de Janeiro. Formado em Ciências Sociais pela Faculdade de Filosofia da Universidade de São Paulo - USP, em 1942. Neste mesmo ano, ingressou no corpo docente da Faculdade de Filosofia da USP, como primeiro assistente em sociologia, no qual permaneceu até 1958 (ALVARENGA, 2015, p. 19).

Sobre o falecimento de Antonio Candido,

Nesta madrugada de 12 maio [2017] morreu Antonio Candido, escritor, crítico literário, sociólogo e Professor Emérito da USP e Unesp e doutor honoris causa da Unicamp e UFPE. Ele estava internado há quase uma semana no Hospital Albert Einstein para tratar de uma obstrução gástrica. O velório está sendo realizado no próprio hospital até as 17 horas de hoje. Neste sábado, será realizada uma cerimônia de cremação apenas para família e amigos (PROFESSOR ANTONIO CANDIDO MORRE, 2017)

Sobre Gilda de Mello e Souza a imprensa noticiou:

Gilda Rocha de Mello e Souza, professora emérita da Faculdade de Filosofia, Letras e Ciências Humanas da Universidade de São Paulo (FFLCH/USP), morreu na tarde de domingo (26/12[2005]), em São Paulo, aos 86 anos. Uma das principais pesquisadoras na área de estética e filosofia da arte, era esposa do crítico literário e professor Antonio Candido de Mello e Souza, com quem teve três filhas. Nasceu em São Paulo em 1919. Passou a infância na fazenda de seus pais em Araraquara, vindo para São Paulo em 1930 para fazer o curso secundário no Colégio Stafford, onde se diplomou no fim de 1934. Em 1937, ingressou na Faculdade de Filosofia, Ciências e Letras da USP, recebendo em 1940 o grau de bacharel em filosofia. No mesmo ano, fez o curso de formação 
de professores e recebeu o grau de licenciada. Em 1943, foi nomeada assistente da Cadeira de Sociologia I, então ocupada por Roger Bastide. Em 1950, recebeu o grau de doutora em ciências sociais com a tese. A moda no século XIX, publicada em 1952 na Revista do Museu Paulista (MORRE AOS 86 ANOS, 2005).

Dando sequência à pesquisa, entende-se que a contextualização biográfica informativa situando os envolvidos neste carteado internacional é relevante sob o ponto de vista da compreensão do lugar de fala que cada um exerce neste diálogo epistolar.

A partir desta breve reflexão, é significativo reconhecer a importância de se trabalhar a epistolografia como fonte de pesquisa e a necessidade de preservar o suporte papel, materialidade das cartas pesquisadas. A preservação documental é, de fato imprescindível à preservação da memória, o que é necessário considerar a partir da seguinte reflexão:

[há] necessidade de preservação do conjunto de bens culturais que integram o patrimônio brasileiro, fazendo menção, em particular, ao papel enquanto categoria tipológica de bem cultural a ser preservado: “ou começamos a cuidar de nossos papéis, onde estão contidas informações, dados, e valores que traçam a trajetória evolutiva, ou vamos carecer dessas informações, fundamentais na explicitação do futuro" [...] "o papel é o suporte de grande parte da nossa informação histórica. E se esse suporte não merecer um trato adequado, desaparece a informação que nele foi depositada em tempos passados" (CASTRO, 2010, p. 42).

A partir desta afirmação é possível concluir que é indeclinável preservar os documentos para não ter que restaurar no futuro, pois, por meio das informações registradas nas fontes epistolográficas, é possível esclarecer lacunas histórico-literárias antes inexplicáveis.

As instituições museológicas ou similares são guardiãs e disseminadoras da memória, assumindo o lugar de representar e recuperar a realidade dos escritores, sua vida literária, pessoal e social, buscando no passado informações relevantes que são possíveis de alterar estudos passados e sustentar estudos futuros.

\section{A DOAÇÃO: RECEIOS, CONFIABILIDADE E AMIZADE}




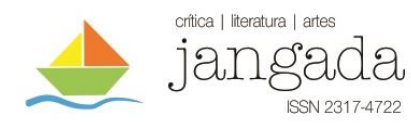

A forma como o museu se apresentará ao público decide o seu destino.

Claudia Reis

O exercício de amizade epistolográfica estabelecido entre Murilo Mendes (correspondência ativa) e Antonio Candido de Mello e Souza e Gilda de Mello e Souza ocorreu entre os anos de 1958 e 1972.

Parte desta pesquisa teve seu início com a elaboração de uma edição anotada desta correspondência, defendida como Dissertação de Mestrado Acadêmico, por Vanilda Alvarenga (2015), apresentada ao Centro de Ensino Superior de Juiz de Fora, em Minas Gerais, orientada pela autora deste artigo. Alvarenga trabalhou com 15 cartas e 2 cartões, (2015), entretanto, neste ano de 2019 foram localizadas 16 cartas e 2 cartões, em sua maioria enviadas de Roma, apenas uma, foi enviada de Lisboa.

Estes documentos encontram-se sob a guarda no Museu de Arte Murilo Mendes MAMM, administrado pela Universidade Federal de Juiz de Fora - UFJF, compondo o Fundo do titular. Entretanto, o olhar de cada pesquisador descobrirá uma outra vertente original num mesmo arquivo, portanto, sob um novo olhar a pesquisa que se encontra em andamento é a preparação de um Dossiê Inventário da Série Correspondência Pessoal do Escritor Murilo Mendes, fundamentado no modelo desenvolvido pelo Arquivo Museu de Literatura Brasileira da Fundação Casa de Rui Barbosa iniciando com as cartas enviadas a Antonio Candido e por ele doadas ao Museu de Arte Murilo Mendes no ano de 2009.

Segundo o Plano Museológico do MAMM (2017), o trabalho de guarda dos acervos por ele custodiados segue as diretrizes dos instrumentos da política nacional de museus do IBRAM contidas no Plano Nacional Setorial de Museus - PNSM, (2010-2020) e no Plano Nacional de Educação Museal - PNEM.

Não menos importante foi a adoção dos preceitos estabelecidos nos documentos internacionais de proteção ao patrimônio cultural como Memória do Mundo da UNESCO e Conservação Preventiva de Gael de Guichen do ICCROM.

Acredita-se que a confiabilidade na Instituição pública possuidora deste referencial técnico e político tenha gerenciado as ações de doação do escritor Antonio Candido. Para isso o processo de doação teve seu início com uma carta enviada por Antonio Candido de Mello e Souza, de São Paulo em 7 de abril de 2009, a José Alberto Pinho Neves, então, Pró-Reitor de Cultura da Universidade Federal de Juiz de Fora, na qual Candido assim se referia: 
Carta de doação. Oferecimento de doação incondicional ao Centro de Estudos

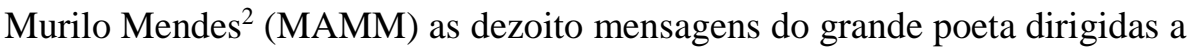
mim e a minha falecida mulher. Isso foi sugestão de Murilo Marcondes de Moura, a quem entreguei o pequeno acervo para que o faça chegar às suas mãos (CANDIDO, 2009, Carta).

Em 2 de fevereiro de 2010, José Alberto Pinho Neves envia uma carta de Juiz de Fora a Antonio Candido acusando o recebimento do respectivo acervo e agradecendo a doação das 18 mensagens do poeta Murilo Mendes ao referido Museu. Em 14 de fevereiro de 2010, Antonio Candido responde a Pinho Neves dizendo que recebeu sua carta datada do dia 2, acusando o recebimento das mensagens de Murilo Mendes por ele oferecidas com prazer a Universidade Federal de Juiz de Fora, encerrando, assim, o processo de doação.

\section{AS CARTAS NÃO DEIXAM DE SER CARTAS: INVENTÁRIO}

A correspondência escrita por Murilo Mendes, enviada a Antonio Candido de Mello e Souza e Gilda de Mello e Souza encontra-se em bom estado de conservação com raras intervenções de insetos de papel, conforme a descrição física do manuscrito registrada no quadro abaixo.

Uma das etapas de trabalho por que passa quem pesquisa em fontes primárias é definir os critérios norteadores para a elaboração dos dossiês que são conjuntos documentais descritos enquanto unidade arquivística. Um documento como uma carta, pode tratar de vários assuntos e misturar várias esferas de atuação do titular, dizendo respeito tanto a suas atividades funcionais quanto à sua participação literária e mesmo sobre sua vida pessoal. Estes resumos ficam reunidos nos inventários dos arquivos, que são os instrumentos aos quais os pesquisadores têm acesso, ou seja, a importância da elaboração dos inventários é que os mesmos permitem conhecer o conteúdo dos arquivos, e solicitar o material integral que possa interessar

\footnotetext{
${ }^{2}$ Cabe aqui um esclarecimento: A origem do MAMM está vinculada ao extinto Centro Murilo Mendes (CMM) a partir da doação de parte da biblioteca particular do poeta Murilo Mendes por sua viúva, senhora Maria da Saudade Cortesão Mendes. A UFJF inaugurou, em 27 de agosto de 1994, no prédio situado na Avenida Rio Branco n. ${ }^{\circ}$ 3.372, o Centro de Estudos Murilo Mendes (CEMM) reformado e adaptado para receber a biblioteca particular e a coleção de artes visuais, adquirida pelo Governo Brasileiro. A atuação do CEMM se deu até o final do mês de dezembro de 2005, quando a UFJF realiza a reforma no prédio de sua antiga reitoria - Rua Benjamin Constant, $\mathrm{n}^{\circ}$ 790, Centro - e inaugura neste espaço o MAMM, transferindo o acervo do poeta até então alocado no CEMM. (PLANO MUSEOLÓGICO 2015/2018). Retificando a doação foi feita ao Museu de Arte Murilo Mendes e não ao Centro de Estudos Murilo Mendes, conforme registrado por Antonio Candido de Mello e Souza em sua carta de doação.
} 
junto a instituição que detém a guarda deste acervo. Portanto, disponibilizar a informações inventariadas em meio eletrônico e disponibilizá-las a acesso público via internet é dar credibilidade a este tipo de pesquisa.

Para a elaboração desta série correspondência pessoal foram adotados os seguintes critérios:

1. para efeito de índice as cartas e cartões foram numerados de 1 a 18, em fonte 12 , com espaçamento simples;

2. após o índice, foram registrados os dados de cada carta ou cartão, informando o remetente, o destinatário, o local de envio da correspondência e o assunto de acordo com a organização arquivística de elaboração de inventários de escritores do Arquivo Museu de Literatura da Fundação Casa de Rui Barbosa (AMLB/FCRB) no Rio de Janeiro;

3. O registro das cartas nas citações diretas, indiretas e referências finais respeitaram as normas da ABNT (2018);

4. Os nomes Murilo Mendes e Antonio Candido foram representados quando necessário pelas abreviaturas M.M e A.C, respectivamente.

\begin{tabular}{|l|l|l|}
\hline Índice & \multicolumn{1}{|c|}{ Correspondência } & \multicolumn{1}{c|}{ Assunto } \\
\hline 1 & $\begin{array}{l}\text { MENDES, M. } \\
\text { Carta a Antônio Candido } \\
\text { de Mello e Souza, Gilda } \\
\text { de Mello e Souza. Roma, } \\
15 \text { fev. 1958. }\end{array}$ & $\begin{array}{l}\text { Solicitação de um artigo sobre o poeta Ungaretti, } \\
\text { em comemoração ao seu 70 aniversário. Murilo } \\
\text { Mendes sugere um texto curto e informa que a } \\
\text { tradução será feita na Itália. }\end{array}$ \\
\hline $\begin{array}{l}\text { MENDES, M. } \\
\text { Carta a Antonio Candido } \\
\text { de Mello e Souza. Roma, } \\
10 \text { mar. 1958. }\end{array}$ & $\begin{array}{l}\text { Parabeniza o casal pelo nascimento da filha, } \\
\text { elogia os artigos de Antonio Candido, } \\
\text { especialmente o dedicado a Stene Ohal e } \\
\text { pergunta quando será publicada a obra história da } \\
\text { literatura brasileira, de autoria de A. C. }\end{array}$ \\
\hline 3 & $\begin{array}{l}\text { MENDES, M. } \\
\text { Carta a Antonio Candido } \\
21 \text { abr. 1958. }\end{array}$ & $\begin{array}{l}\text { Solicitação urgente do texto em homenagem ao } \\
\text { poeta Ungaretti. Reclama da morosidade dos } \\
\text { correios. Informa que Manuel Bandeira já enviou } \\
\text { sua contribuição sobre o poeta italiano e elogia a } \\
\text { obra de A. C. dedicada a Graciliano Ramos e o } \\
\text { ensaio de Gilda de Mello e Souza sobre moda e } \\
\text { sociedade. Informa que enviará a A.C. um } \\
\text { exemplar da obra Poesias (quase se completas) } \\
\text { que estariam em edição nos prelos de José } \\
\text { Olympio. }\end{array}$ \\
\hline 4 & $\begin{array}{l}\text { MENDES, M. } \\
\text { Carta a Antonio Candido } \\
\text { de Mello e Souza. Roma, } \\
17 \text { maio 1958. }\end{array}$ & $\begin{array}{l}\text { Elogia o trabalho dos correios e agradece o envio } \\
\text { do artigo junto com a notícia do 3 }{ }^{\circ} \text { Sputnik. } \\
\text { Comunica o falecimento de Henri Martineau. }\end{array}$ \\
\hline
\end{tabular}




\begin{tabular}{|c|c|c|}
\hline 5 & $\begin{array}{l}\text { MENDES, M. } \\
\text { Cartão a Gilda de Mello } \\
\text { e Souza. Roma, } 6 \text { dez. } \\
1958 .\end{array}$ & $\begin{array}{l}\text { Agradece a envio do suplemento do Estado de S. } \\
\text { Paulo. Pergunta sobre o livro história da literatura } \\
\text { brasileira de A.C. Felicitações de Boas-festas de } \\
\text { final de ano. }\end{array}$ \\
\hline 6 & $\begin{array}{l}\text { MENDES, M. } \\
\text { Carta a Gilda de Mello e } \\
\text { Souza. Roma, } 16 \text { maio } \\
1959 .\end{array}$ & $\begin{array}{l}\text { Agradece o envio de uma carta nos primeiros } \\
\text { tempos da instalação do casal na cidade de Assis. } \\
\text { M.M comunica que terminou o livro Tempo } \\
\text { Espanhol. } \\
\text { Pergunta novamente sobre quando sai a História } \\
\text { da Literatura Brasileira, produção de Antonio } \\
\text { Candido. }\end{array}$ \\
\hline 7 & $\begin{array}{l}\text { MENDES, M. } \\
\text { Carta a Antonio Candido } \\
\text { de Mello e Souza. } \\
\text { Lisboa, } 29 \text { jul. } 1959 .\end{array}$ & Agradece a indicação de obras sugeridas por A.C. \\
\hline 8 & $\begin{array}{l}\text { MENDES, M. } \\
\text { Carta a Antonio Candido } \\
\text { de Mello e Souza. Roma, } \\
1 \text { fev. } 1960 .\end{array}$ & $\begin{array}{l}\text { Indicação do nome de A.C. junto a G } \\
\text { "Columbianum" (organização cultural fundada } \\
\text { em Genova, cujo escopo principal consiste em } \\
\text { trazer para a Europa a problemática da América } \\
\text { Latina), para apresentar, com relativa urgência, } \\
\text { um ensaio sobre uma figura ilustre do nosso país, } \\
\text { [Brasil] um "emancipador mental". Sugeriu os } \\
\text { nomes Silvio Romero; Euclides; Castro Alves; ou } \\
\text { Mário de Andrade. O ensaio deveria ter } \\
\text { implicações sociológicas e políticas. Informa que } \\
\text { a AGIR comprou 500 exemplares do último livro } \\
\text { Tempo Espanhol publicado recentemente em } \\
\text { Lisboa. Comenta sobre a questão da Argélia e o } \\
\text { fascismo. }\end{array}$ \\
\hline 9 & $\begin{array}{l}\text { MENDES, M. } \\
\text { Carta a Antonio Candido } \\
\text { de Mello e Souza. Roma, } \\
23 \text { out. } 1960 .\end{array}$ & $\begin{array}{l}\text { Agradece as manifestações de pesar pelo } \\
\text { falecimento do sogro, Jaime Cortesão. }\end{array}$ \\
\hline 10 & $\begin{array}{l}\text { MENDES, M. } \\
\text { Carta a Antonio Candido } \\
\text { de Mello e Souza. Roma, } \\
14 \text { abr. } 1962 .\end{array}$ & $\begin{array}{l}\text { Agradecimentos pelos envios postais: livros e } \\
\text { jornais. }\end{array}$ \\
\hline 11 & $\begin{array}{l}\text { MENDES, M. } \\
\text { Carta a Antonio Candido } \\
\text { de Mello e Souza. Roma, } \\
31 \text { mar. } 1963 .\end{array}$ & $\begin{array}{l}\text { Os signatários conversam sobre processo de } \\
\text { criação, agradece a Gilda a escrita do artigo "A } \\
\text { maçã no escuro" }\end{array}$ \\
\hline 12 & $\begin{array}{l}\text { MENDES, M. } \\
\text { Cartão a Antonio } \\
\text { Candido de Mello e } \\
\text { Souza, Gilda de Mello e } \\
\text { Souza. Roma, } 31 \text { dez. } \\
\text { 1963/1964. }\end{array}$ & Votos de Feliz Ano Novo. \\
\hline 13 & MENDES, M. & $\begin{array}{l}\text { Felicitações por A.C. ministrar aulas na } \\
\text { Sorbonne. Pergunta sobre quando será publicada } \\
\text { a antologia da literatura brasileira. }\end{array}$ \\
\hline
\end{tabular}




\begin{tabular}{|l|l|l|}
\hline & $\begin{array}{l}\text { Carta a Antonio Candido } \\
\text { de Mello e Souza. Roma, } \\
\text { 15 mar. 1964. }\end{array}$ & \\
\hline 14 & $\begin{array}{l}\text { MENDES, M. } \\
\text { Carta a Antonio Candido } \\
\text { de Mello e Souza, Gilda } \\
\text { de Mello e Souza. Roma, } \\
\text { 26 abr.1964. }\end{array}$ & $\begin{array}{l}\text { Apresenta Luciana Picchio e divulga sua mais } \\
\text { nova publicação sobre a história do teatro } \\
\text { português. Solicita a A.C que divulgue a obra da } \\
\text { pesquisadora no Brasil. Descreve o livro e } \\
\text { informa preços. }\end{array}$ \\
\hline 15 & $\begin{array}{l}\text { MENDES, M. } \\
\text { Carta a Antonio Candido } \\
\text { de Mello e Souza. Roma, } \\
\text { 14 jan. 1965. }\end{array}$ & $\begin{array}{l}\text { Agradece a A.C. o envio da obra Formação da } \\
\text { Literatura Brasileira que finalmente foi } \\
\text { publicada. Pergunta se A.C recebeu o envio da } \\
\text { obra Poesias feito por intermédio da editora José } \\
\text { Olympio. }\end{array}$ \\
\hline 16 & $\begin{array}{l}\text { MENDES, M. } \\
\text { Carta a Antonio Candido } \\
\text { de Mello e Souza. Roma, } \\
\text { 16 jun. 1968. }\end{array}$ & $\begin{array}{l}\text { Apresentação do Professor José da Costa } \\
\text { Miranda, da Universidade de Roma que irá ao } \\
\text { Brasil a fim de fazer pesquisas sobre certos temas } \\
\text { da nossa literatura. Solicita a A. C. que o receba } \\
\text { em convivência humana. }\end{array}$ \\
\hline 17 & $\begin{array}{l}\text { MENDES, M. } \\
\text { Carta a Antonio Candido } \\
\text { de Mello e Souza. Roma, } \\
11 \text { out. 1968. }\end{array}$ & $\begin{array}{l}\text { M. M. comunica a A.C. que o seu livro em prosa, } \\
\text { inéditos, escritos nos últimos anos, Figuras, é } \\
\text { dedicado a Antonio Candido de Mello e Souza. } \\
\text { Comenta brevemente o conteúdo do livro e seu } \\
\text { processo de criação. }\end{array}$ \\
\hline 18 & $\begin{array}{l}\text { MENDES, M. } \\
\text { Carta a Antonio Candido } \\
\text { de Mello e Souza. Roma, } \\
\text { 21 nov. 1972. }\end{array}$ & $\begin{array}{l}\text { Desculpa-se por não escrever e acusa doença para } \\
\text { justificar tal ato. Ratifica a importância da } \\
\text { amizade e do afeto que os une. }\end{array}$ \\
\hline
\end{tabular}

\section{CONSIDERAÇÕES FINAIS}

A organização, a descrição e a elaboração deste inventário da série correspondência de Murilo Mendes visam a considerar o grande número de pesquisadores interessados num período da vida deste poeta que mantém uma relação amistosa e infrequente com o escritor Antonio Candido e sua esposa Gilda.

Estas cartas, de um modo geral, revelaram dados de ordem pessoal do destinatário e dos remetentes, além de breves registros sobre processo de criação de ambos envolvidos no carteado e de terceiros por ele citados. Estavam presentes solicitações de colaboração em jornais e revistas de ambos os escritores ressaltando o papel que desempenharam no cenário cultural nacional e internacional.

Sobre o processo de criação e ensaios críticos de ambos, Murilo Mendes com frequência se mostrava ansioso por ler algumas resenhas críticas que Antonio Candido elaborou a respeito 
de seus livros como a obra Poesias, por exemplo. Em vários momentos missivísticos solicitou tal texto crítico de forma insistente.

O poeta juiz-forano elogia e agradece, em várias cartas, o apoio empreendido por Antonio Candido quanto à divulgação das obras do poeta Ungaretti como, por exemplo, publicar um ensaio sobre o escritor italiano em uma página no jornal Estado de São Paulo referente ao escritor Ungaretti, que em diversas conversas com Murilo revela seu interesse pelo Brasil.

Murilo Mendes comenta que o estudo desenvolvido por Antonio Candido sobre a arte de Graciliano Ramos é uma investigação em profundidade com agudas observações sobre o homem enquanto ser social, fato que despertou a leitura de Memórias de Cárcere, escrita por Graciliano Ramos, cuja obra não é conhecida por Murilo Mendes.

Sobre o livro, História da Literatura Brasileira, produção de Antonio Candido, Murilo Mendes comenta que foi um enorme prazer constatar que o ensaísta brasileiro encontrou, nesta pesquisa, um novo caminho de orientação crítica, que se distingue ao mesmo tempo do método impressionista, evidentemente esgotado. Durante todo o carteado esta obra que estava em elaboração foi denominada e tratada como História da Literatura Brasileira, sendo publicada, posteriormente, com o nome de Formação da Literatura Brasileira em 2 volumes.

Sobre terceiros por eles citados, o poeta italiano Ungaretti foi o eixo das conversas. Elogia o artigo escrito por Antonio Candido sobre o poeta italiano, afirmando que Candido conseguiu fixar uma excelente crítica em um texto curto e de grande densidade. Prometeu que logo a saída da publicação desta homenagem enviaria a Antonio Candido um exemplar.

Sobre momentos históricos e políticos Murilo Mendes se detém na problemática vivenciada na Argélia e afirma que a burguesia francesa terá que pagar duramente por seu egoísmo e incompreensão na virada de página do mundo. Todas essas manobras da direita, entre o vulgar e o trágico, não poderão deixar de conduzir ao desastre. Critica a França dizendo que no país que fez a Revolução, tais coisas são, a seu ver, particularmente absurdas e sinistras.

A correspondência emitida por Murilo Mendes e recebida por Antonio Candido e Gilda de Mello e Souza legitima a reconhecida importância dos signatários enquanto companheiros de geração.

Importa ressaltar que a forma como Murilo Mendes se refere a Antonio Candido e Gilda, confirma o grau de amizade entre os escritores, tanto que, para além de ser um documento significativo, uma carta pode ser fonte de inspiração, e como tal atuou para o título desse trabalho. A expressão afetuosos abraços e saudades é uma despedida recorrente utilizada pelo remetente Murilo Mendes em direção ao casal Souza. 
Esta investigação, ainda em andamento, possibilitou identificar e compreender, até o momento, a presença de afinidades discretas e formais entre envolvidos que se sustentavam nos laços da admiração.

Portanto, a este trabalho importa resgatar e conservar a memória dos referidos signatários, redescobrindo e revalorizando suas atuações, dando-lhes oportunidade de serem lidos mais uma vez.

\section{REFERÊNCIAS BIBLIOGRÁFICAS}

ALVARENGA, V. O poeta e o crítico: Murilo Mendes escreve a Antonio Candido. Orientadora: Moema Rodrigues Brandão Mendes. 2015. 110f. Dissertação [Mestrado em Letras]. Centro de Ensino Superior de Juiz de Fora, Juiz de Fora, Minas Gerais, 2015.

CANDIDO, A. [Correspondência]. Destinatário: José Alberto Pinho Neves. São Paulo, 9 abr. 2009. 1 carta.

. [Correspondência]. Destinatário: José Alberto Pinho Neves. São Paulo, 14 fev. 2010. 1 carta.

CASTRO, Aloisio Arnaldo Nunes de. A preservação Documental no Brasil. Notas para uma reflexão histórica. Acervo. Rio de Janeiro: v. 23, n. 2, p. 31-46, jul./dez. 2010. Disponível em http://revista.arquivonacional.gov.br/index.php/revistaacervo/article/view/24. Acesso em: 13 jul. 2019.

COMPAGNON, A. A Era das cartas. Belo Horizonte: UFMG, 2019.

COSTA, José Carlos da et al. Representações da memória na literatura e na cultura. Revista Investigações. Pernambuco: UFPE, Vol. 23, nº 1, jan. 2010.

Disponível em:

http://www.repositorios.ufpe.br/revistas/index.php/INV/article/view/1338. Acesso em: 28 jun. 2019.

CURY, Maria Zilda Ferreira. A pesquisa em acervos e o remanejamento da crítica. Manuscrítica. Revista de Crítica Genética São Paulo: USP/APCG,1993, n. 3, p. 78-93.

Disponível em:

http://www.revistas.fflch.usp.br/manuscritica/article/view/853/770. Acesso em 14 jul. 2019. GUIMARÃES, Júlio Castanõn. Murilo Mendes. São Paulo: Brasiliense, 1986.

HAY, Louis. A literatura sai dos arquivos. In: SOUZA, Eneida Maria de; MIRANDA, Wander Mello (Org.). Arquivos literários. São Paulo: Ateliê Editora, 2003, p. 65-81.

MENDES, M. [Correspondência]. Destinatário: Antonio Candido de Mello e Souza, Gilda de Mello e Souza. Roma, 15 fev. 1958. 1 carta.

[Correspondência]. Destinatário: Antonio Candido de Mello e Souza, Gilda de Mello e Souza. Roma, 10 mar. 1958. 1 carta.

[Correspondência]. Destinatário: Antonio Candido de Mello e Souza. Roma, 21 abr. 1958. 1 carta. 
[Correspondência]. Destinatário: Antonio Candido de Mello e Souza. Roma, 17 maio 1958. 1 carta.

. [Correspondência]. Destinatário: Gilda de Mello e Souza. Roma, 6 dez. 1958. 1 carta.

. [Correspondência]. Destinatário: Gilda de Mello e Souza. Roma, 16 maio 1959. 1 carta. 1959. 1 carta.

[Correspondência]. Destinatário: Antonio Candido de Mello e Souza. Lisboa, 29 jul.

. [Correspondência]. Destinatário: Antonio Candido de Mello e Souza. Roma, 1 fev. 1960. 1 carta.

. [Correspondência]. Destinatário: Antonio Candido de Mello e Souza. Roma, 23 out. 1960. 1 carta.

. [Correspondência]. Destinatário: Antonio Candido de Mello e Souza. Roma, 14 abr. 1962. 1 carta.

[Correspondência]. Destinatário: Antonio Candido de Mello e Souza. Roma, 31 mar. 1963. 1 carta.

[Correspondência]. Destinatário: Antonio Candido de Mello e Souza, Gilda de Mello e Souza. Roma, 31 dez. 1963/1964. 1 cartão.

. [Correspondência]. Destinatário: Antonio Candido de Mello e Souza. Roma, 15 mar. 1964. 1 carta.

- [Correspondência]. Destinatário: Antonio Candido de Mello e Souza, Gilda de Mello e Souza. Roma, 26 abr.1964. 1 carta.

. [Correspondência]. Destinatário: Antonio Candido de Mello e Souza. Roma, 14 jan. 1965. 1 carta.

[Correspondência]. Destinatário: Antonio Candido de Mello e Souza. Roma, 16 jun. 1968. 1 carta.

[Correspondência]. Destinatário: Antonio Candido de Mello e Souza. Roma, 11 out. 1968. 1 carta.

[Correspondência]. Destinatário: Antonio Candido de Mello e Souza. Roma, 21 nov. 1972. 1 carta.

MORRE AOS 86 ANOS Gilda de Mello e Souza. São Paulo: Agência FAPESP, 2005.

Disponível em: http://agencia.fapesp.br/gilda-de-mello-e-souza-morre-aos-86-anos/4831/ Acesso em: 18 jul. 2019.

NEVES, J.A. [Correspondência]. Destinatário: Antonio Candido. Juiz de Fora, 2 feve. 2010. 1 carta.

PLANO MUSEOLÓGICO Museu de Arte Murilo Mendes - 2015/2018. Juiz de Fora: UFJF, 2017, p. 6. Disponível em:

http://www.museudeartemurilomendes.com.br/r/wpcontent/uploads/2017/10/Plano_09102017 .pdf. Acesso em 17 jul. 2019.

PROFESSOR ANTONIO CANDIDO MORRE aos 86 anos. Jornal da USP, São Paulo, 2017.

Disponível em: https://jornal.usp.br/universidade/professor-antonio-candido-morre-aos-98anos/. Acesso em: 19 jul. 2019. 
REIS, Cláudia Barbosa. Museus voltados para a literatura: ainda um desafio no Brasil. Verbo de Minas, v.11, n. 19, jan.-jul. 2011, p. 255-264. Disponível em: http://seer.cesjf.br/index.php/verboDeMinas/article/view/361 Acesso em: 20 jul. 2019.

VASCONCELLOS, Eliane. Intimidade das confidências. Teresa: revista de literatura brasileira, São Paulo, v. 8, n. 9, p. 372-389, 2008.

VINCENT-BUFFAULT, Anne. Da amizade: uma história do exercício da amizade nos séculos XVIII e XIX. Rio de Janeiro: Jorge Zahar, 1996. 